\title{
Susceptibility of embryogenic and organogenic tissues of maritime pine (Pinus pinaster) to antibiotics used in Agrobacterium-mediated genetic transformation
}

\author{
S. Tereso $\cdot$ C. Miguel $\cdot$ J. Maroco $\cdot$
}

M. M. Oliveira

Received: 4 August 2005/ Accepted: 8 June 2006/Published online: 5 October 2006

(C) Springer Science+Business Media B.V. 2006

\begin{abstract}
The effects of antibiotics commonly used in Agrobacterium-mediated transformation were studied on Pinus pinaster tissues. Embryogenic tissue growth from three embryogenic lines and adventitious bud induction from cotyledons from three open-pollinated seed families were analysed. Cefotaxizme, carbenicillin and timentin commonly used for Agrobacterium elimination, at concentrations of $200-400 \mathrm{mg} \mathrm{l}^{-1}$ did not inhibit the embryogenic tissue growth on filter paper nor as clumps. Adventitious bud induction and bud number were significantly reduced for one of the tested families when using $400 \mathrm{mg} \mathrm{l}^{-1}$ cefotaxime or timentin. The selection agent kanamycin significantly inhibited growth of embryogenic tissue on filter paper in all the embryogenic lines and concentrations tested (20-50 $\left.\mathrm{mg} \mathrm{l}^{-1}\right)$.
\end{abstract}

S. Tereso · C. Miguel · M. M. Oliveira $(\bowtie)$

Forest Biotech, IBET/ITQB, Quinta do Marquês,

2784-505 Oeiras, Portugal

e-mail: mmolive@itqb.unl.pt

J. Maroco

Grupo de Estatística e Matemática, Instituto Superior de Psicologia Aplicada, Rua Jardim do Tabaco 34, 1149-041 Lisboa, Portugal

M. M. Oliveira

Department of Biologia Vegetal, , Faculdade de Ciências de Lisboa, Campo Grande, 1749-016 Lisboa, Portugal
Kanamycin also inhibited growth of embryogenic clumps after two subcultures at $5-50 \mathrm{mg} \mathrm{l}^{-1}$. In cotyledons, kanamycin inhibited adventitious bud formation in the three seed families used, regardless of the concentrations tested (5$25 \mathrm{mg} \mathrm{l}^{-1}$ ). There was a significant effect of the seed family on the bud induction and the number of adventitious buds produced. From the results obtained, we propose the use of timentin to eliminate Agrobacterium in transformation experiments, at concentrations of $400 \mathrm{mg} \mathrm{l}^{-1}$ for embryogenic tissues and of $300 \mathrm{mg} \mathrm{l}^{-1}$ for cotyledons. For selection of transformed tissues carrying the kanamycin resistance gene, kanamycin should be used at $20 \mathrm{mg} \mathrm{l}^{-1}$ for embryogenic tissues on filter paper, at $5 \mathrm{mg} \mathrm{l}^{-1}$ when clumps are in direct contact with the selection medium, and bellow $5 \mathrm{mg} \mathrm{l}^{-1}$ for adventitious bud induction.

Keywords Adventitious bud induction · Carbenicillin - Cefotaxime - Kanamycin · Somatic embryogenesis - Timentin
Abbreviations
BA 6-benzyladenine
$\mathrm{CH}$ Casein hydrolysate
2,4-D 2,4-dichlorophenoxyacetic acid
FW Fresh weight
NAA Naphthalene acetic acid
PGR Plant growth regulators 


\section{Introduction}

The successful Agrobacterium-mediated plant transformation requires efficient procedures to eliminate the bacteria following cocultivation, and for subsequently selecting the transformed cells. These procedures frequently involve the presence of one or more antibiotics in culture media. The most commonly used antibiotics for Agrobacterium elimination include the $\beta$-lactam antibiotics cefotaxime and carbenicillin. Cefotaxime is a cephalosporin antibiotic that has been frequently used in genetic transformation of various conifer species (Hood et al. 1990; Levée et al. 1997, 1999; Humara et al. 1999; López et al. 2000; Klimaszewska et al. 2001; Le et al. 2001). It has high resistance to $\beta$-lactamase activity but in conifers it can inhibit adventitious bud regeneration (Holland et al. 1997) and embryo development (Tsang et al. 1989; Sarma et al. 1995). Carbenicillin has been used for Pinus radiata (Cerda et al. 2002), but in Picea sitchensis it inhibited the development of somatic embryos and tissue growth (Sarma et al. 1995). Timentin, which is a combination of ticarcillin with clavulanic acid that is a specific $\beta$-lactamase inhibitor (Verbist and Verhaegen 1986), has been selected for transformation studies in some conifers (Wenck et al. 1999; Le et al. 2001; Charity et al. 2002; Grant et al. 2004). In Pinus pinaster French genotypes, neither augmentin (amoxicillin with clavulanic acid) nor a mixture of carbenicillin with cefotaxime were effective in Agrobacterium elimination from all the embryogenic lines tested (Trontin et al. 2002). Nevertheless, no systematic study of the effects of such antibiotics on cultured tissues has been reported for this species. Kanamycin has been used for selection of transformed tissues in various conifer species (Levée et al. 1997, 1999; Klimaszewska et al. 2001). Other reports showed that low concentrations of this antibiotic could impair the embryogenic potential (Mihaljević et al. 2001) and the organogenic response (Humara and Ordás 1999). Effects of kanamycin on $P$. pinaster tissues have not been reported.

This work aimed to analyse the effects of cefotaxime, carbenicillin, timentin and the selective antibiotic kanamycin, at different concentrations, on embryogenic tissues growth and on adventitious bud induction from cotyledons. The most suitable antibiotics and respective concentrations to use in Agrobacterium-mediated transformation were determined.

\section{Material and methods}

Plant material and culture conditions

Embryogenic tissues derived from immature zygotic embryos of $P$. pinaster were induced as described by Miguel et al. (2004) and used to study tissue growth [changes in fresh weight (FW)] under different antibiotic treatments. Small portions of embryogenic tissue (clumps) with approximately $500 \mathrm{mg}$ each were subcultured every 14 days in maintenance medium consisting of DCR (Gupta and Durzan 1985) basal medium containing 9.0 $\mu \mathrm{M}$ 2,4-dichlorophenoxyacetic acid (2,4-D) (Duchefa Biochemie, Haarlem, The Netherlands) and 2.2 $\mu \mathrm{M}$ 6-benzyladenine (BA) (Duchefa Biochemie), and supplemented with $440 \mathrm{mg} \mathrm{l}^{-1}$ filter sterilized L-glutamine (Duchefa Biochemie) and with $500 \mathrm{mg} \mathrm{l}^{-1}$ casein hydrolysate $(\mathrm{CH})$ (Duchefa Biochemie) (Miguel et al. 2004). Cultures were kept in the dark. The effect of antibiotics on embryogenic suspensions plated onto filter paper was tested for embryogenic lines $31 / 668 / 00,82 / 758 / 00$ and $68 / 455 / 00$. As previously evaluated (Miguel et al. 2004), these lines were able to produce mature somatic embryos after exposure to maturation conditions. Embryogenic suspensions from each embryogenic line were freshly prepared by spreading the embryogenic tissue from a 7-day-old subculture in liquid maintenance medium (200 mg FW ml${ }^{-1}$ ). Tissue was disintegrated with a cut pipette tip. One millilitre of the suspension was plated onto a filter paper (Whatman n.2, $5.5 \mathrm{~cm}$ diameter) in a Büchner funnel. A short vacuum pulse was applied to remove the liquid and the filter paper was placed on solid maintenance medium supplemented with antibiotic. The FW of each replicate was recorded after three subcultures of 14 days each. 
Our transformation protocol involves at least one subculture of the embryogenic tissue in filter paper and then isolation and transfer of proliferating embryogenic clumps to solid medium. In order to check if filter paper could interfere with the selection efficiency of the antibiotics used in genetic transformation, embryogenic clumps cultured directly in contact with solid medium were also submitted to antibiotics. Embryogenic line 68/ $455 / 00$ and two other lines also showing good maturation performances, 426/99 and 686/99, were tested. A set of six clumps from a 7-day-old subculture was weighted and transferred directly to solid maintenance medium. The average FW was determined at the end of each subculture (every 14 days). Tissue growth was calculated as the average difference between final and initial FW. For adventitious bud induction, cotyledons of mature seeds from the open-pollinated families 31, 45 and 60 were used. Explants consisted of cotyledon sets isolated from 7-day-old seedlings germinating on $3 \%(\mathrm{w} / \mathrm{v})$ glucose solidified with microagar (Duchefa Biochemie) $7 \mathrm{~g} \mathrm{l}^{-1}$, under a 16-hours photoperiod and light intensity of $35 \mu \mathrm{E} \mathrm{m}^{-2} \mathrm{~s}^{-1}$ provided by cool-white fluorescent lamps (TLD 36W/84, Philips, Thailand). Cotyledons were placed horizontally on adventitious bud induction medium GMD (Mohammed et al. 1986) containing $4.45 \mu \mathrm{M}$ BA and $0.54 \mu \mathrm{M}$ naphthalene acetic acid (NAA) with the antibiotic under test, in photoperiod conditions. After 21 days, cotyledons were transferred to GMD basal medium without plant growth regulators (PGR) and containing $1 \mathrm{~g} \mathrm{l}^{-1}$ activated charcoal for 28 days, after which the induction frequency and average number of induced buds per seed were recorded. All cultures were maintained in a growth chamber at $23 \pm 2^{\circ} \mathrm{C}$.

\section{Antibiotics}

All the antibiotics were filter sterilized $(0.22 \mu \mathrm{m}$ pore size) and added to the maintenance or induction media after autoclaving. Kanamycin (Duchefa Biochemie) was tested at 20,30, 40 and $50 \mathrm{mg} \mathrm{l}^{-1}$ for embryogenic tissues plated on filter paper, at $5,10,20,30$ or $50 \mathrm{mg} \mathrm{l}^{-1}$ for embryogenic clumps, and at 5, 7.5, 10, 15, 20 and $25 \mathrm{mg} \mathrm{l}^{-}$ ${ }^{1}$ for cotyledons. Timentin (Duchefa Biochemie) and cefotaxime (Duchefa Biochemie) were tested at 200, 300 and $400 \mathrm{mg} \mathrm{l}^{-1}$ on cotyledons and on freshly prepared embryogenic suspensions plated onto filter paper. The effects of carbenicillin (Sigma, St Louis, MO, USA), timentin and cefotaxime on embryogenic clumps were compared at 200 and $400 \mathrm{mg} \mathrm{l}^{-1}$. Embryogenic and organogenic tissues grown on antibiotic-free media were used as controls.

Statistical analysis

Data in Figs. 1, 2 and 4 was analysed with a twoway ANOVA on Ranks (see Zar 1999) since none of the usual mathematical data transformations were able to validate the assumptions of the parametric ANOVA. Multiple mean rank comparisons between treatments/genotypes were performed as described in Conover (1999) and by a Tukey's HSD on ranks. Induction data in Fig. 3 was analysed with a Qui-square test on bud induction (Yes/No) counts by treatment and family. Data analysis was performed with SPSS (Version 14, SPSS Inc, Chicago, IL, USA) and statistical significance differences were assumed when $p \leq 0.05$.

For embryogenic tissues placed on filter paper, three replicates were used per embryogenic line and experiment, and the experiments were performed twice. In the case of embryogenic clumps, for each antibiotic treatment, nine replicates were used per experiment (corresponding to three replicates for each embryogenic line). For cotyledons of each open-pollinated family and antibiotic treatment, ten replicates (genotypes) were used per experiment and the experiments were performed twice.

\section{Results and discussion}

Antibiotic effect on growth of embryogenic tissues on filter paper

When testing the effect of the antibiotics cefotaxime and timentin on the growth of embryogenic tissues on filter paper, statistical significant differences were found in the growth response between genotypes $(H(2)=111.64 ; p<0.001)$ and between antibiotics $(H(6)=17.277 ; p=0.008)$. Both cefotaxime and timentin at the tested concentrations 

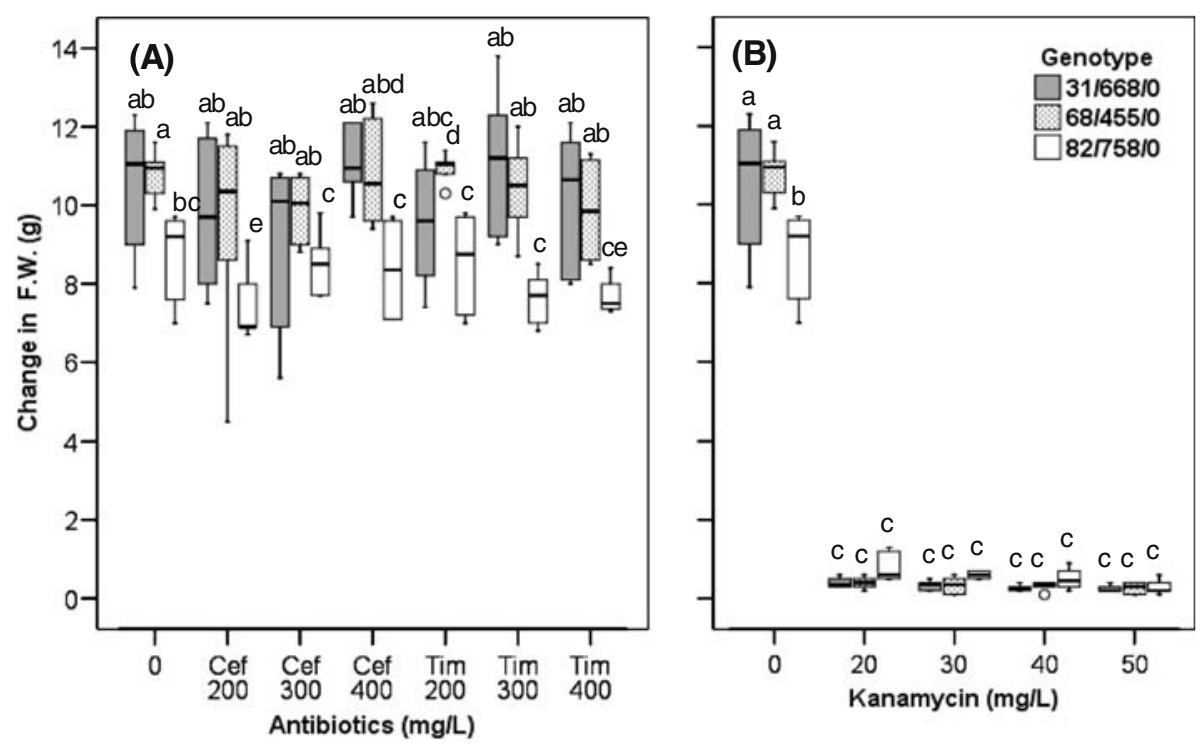

Fig. 1 Effects of cefotaxime, timentin (A) and kanamycin (B) on growth of embryogenic tissues on filter paper, for the embryogenic lines 31/668/00, 82/758/00 and 68/455/ 00. Data are presented as box-plots for the change in

fresh-weight $(F W)$ for a 2 week's subcultures of two independent experiments. Values with different letters are significantly different $(p \leq 0.05)$. Cef cefotaxime, Tim timentin
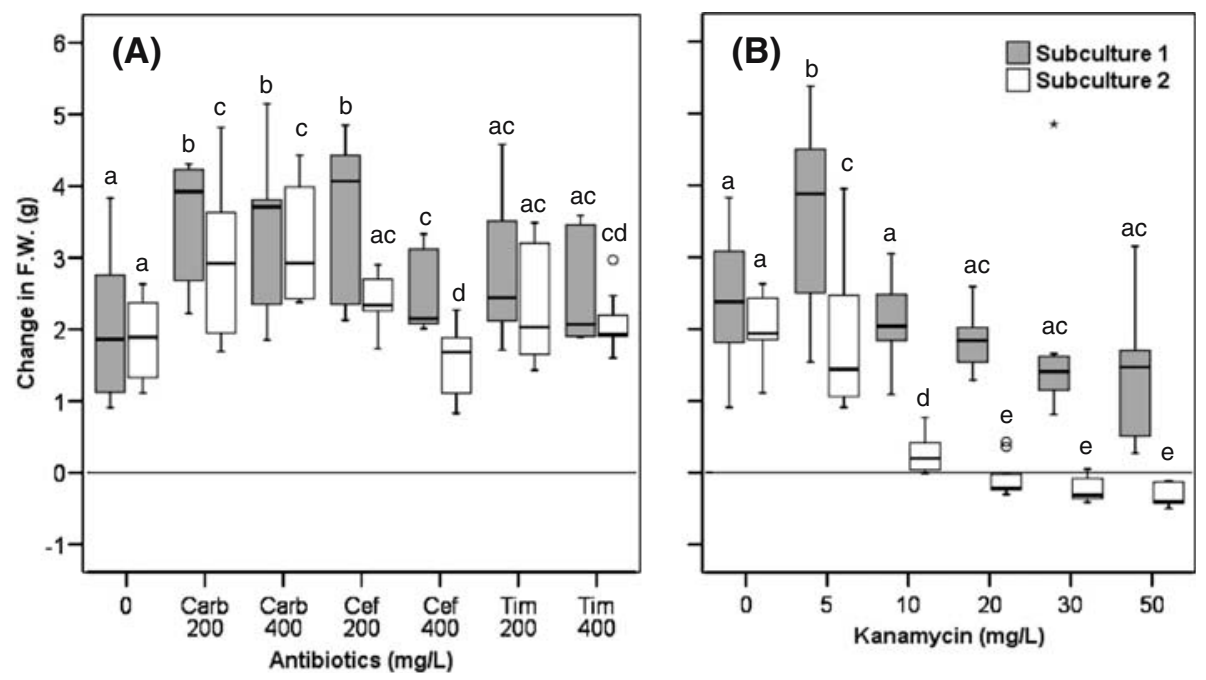

Fig. 2 Effects of carbenicillin, cefotaxime and timentin (A) and kanamycin (B) on growth of embryogenic clumps. Data are presented as box-plots for the change

in fresh-weight $(F W)$ for a 2 -week growth period. Values with different letters are significantly different $(p \leq 0.05)$. Cef cefotaxime, Carb carbenicillin, Tim timentin

had no significant effect on tissue growth of freshly prepared embryogenic suspensions plated on filter paper, as compared to the control, with the exception of $200 \mathrm{mg} \mathrm{l}^{-1}$ cefotaxime (Fig. 1a). The embryogenic line 82/758/00 always showed significantly lower growth than 31/668/00 and 68/455/00, although with no statistical significance. In genetic

transformation experiments using the same Agrobacterium strain (C58pMP90), $200 \mathrm{mg} \mathrm{l}^{-1}$ timentin was used for Pinus taeda and Picea abies embryogenic suspensions (Wenck et al. 1999), whereas $250 \mathrm{mg} \mathrm{l}^{-1}$ cefotaxime was used for Pinus strobus freshly prepared embryogenic suspensions (Levée et al. 1999). Tissue growth from transgenic 

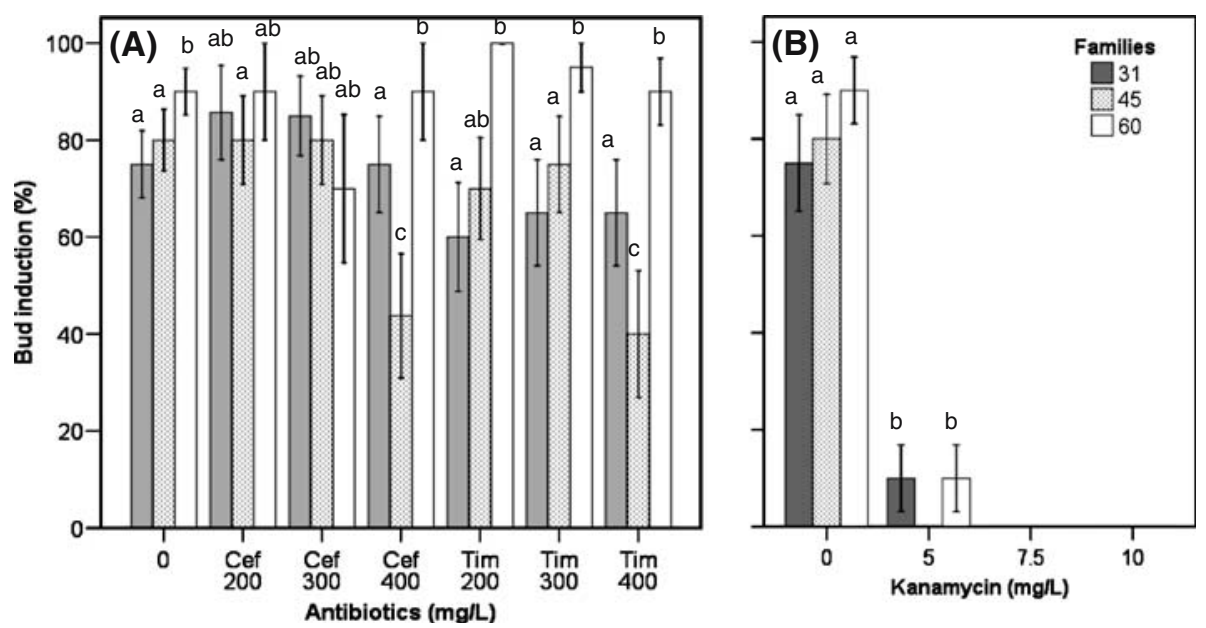

Fig. 3 Effects of cefotaxime and timentin (A) and kanamycin (B) on adventitious bud induction frequency in cotyledons from seed families 31, 45 and 60. Data represent average values $( \pm \mathrm{SEM})$ of two independent experiments with ten replicates each. Cef cefotaxime, Tim timentin
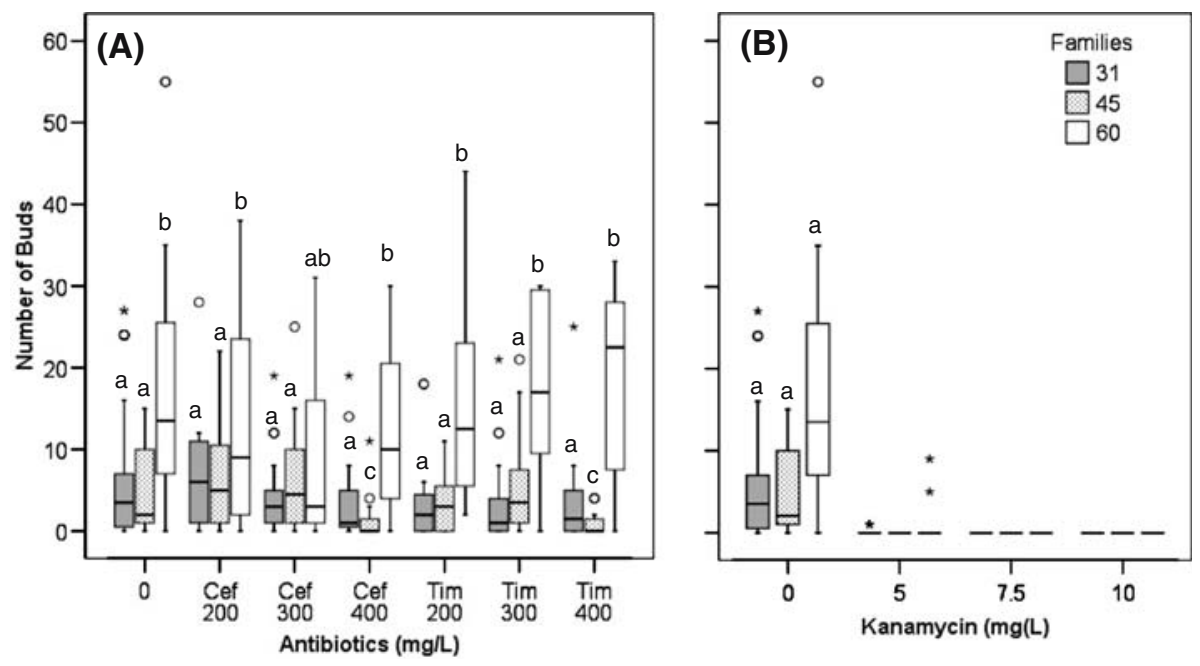

Fig. 4 Effects of cefotaxime and timentin (A) and kanamycin (B) on number of adventitious buds induced per cotyledon sets forming buds from seed families 31,45 and 60. Data represent the box-plot distributions of two

embryogenic suspensions of Picea glauca was not affected by cefotaxime or carbenicillin at 100 $500 \mathrm{mg} \mathrm{l}^{-1}$ or by timentin at $100-400 \mathrm{mg} \mathrm{l}^{-1}$ but $400 \mathrm{mg} \mathrm{l}^{-1}$ timentin was more efficient for Agrobacterium elimination (Le et al. 2001). For $P$. pinaster French genotypes, an antibiotic treatment adequate for all embryogenic lines has not been found, with one line persistently showing Agrobacterium contamination (Trontin et al. 2002). In independent experiments with ten replicates each. Values with different letters are significantly different $(p \leq 0.05)$. Cef cefotaxime, Tim timentin

Portuguese $P$. pinaster genotypes, $400 \mathrm{mg} \mathrm{l}^{-1}$ timentin has been effective for Agrobacterium elimination from nine embryogenic lines on filter paper during transformation experiments (Tereso 2005).

Relative to the kanamycin treatment, there were highly significant differences between the control group and the other groups $(H(4)=52.222$; $p<0.001)$ but the differences between genotypes, 
after accounting for the differences between kanamycin concentrations, were only marginally significant $(H(2)=5.297 ; p=0.07)$. The inhibition by kanamycin of embryogenic tissue growth on filter paper was observed after three subcultures at any of the concentrations tested (Fig. 1b). In the three Portuguese embryogenic lines of $P$. pinaster, $20 \mathrm{mg} \mathrm{l}^{-1}$ kanamycin was enough to inhibit growth of untransformed embryogenic tissues on filter paper. According to the literature, the effective concentration of this antibiotic for selection of Agrobacterium-transformed tissues can vary from 10 to $35 \mathrm{mg} \mathrm{l}^{-1}$ depending on the conifer species (Levée et al. 1999; Wenck et al. 1999; Klimaszewska et al. 2001). In non-transgenic cotyledonary somatic embryos of Picea omonika, $10 \mathrm{mg} \mathrm{l}^{-1}$ kanamycin caused the loss of embryogenic ability (Mihaljević et al. 2001). In P. pinaster, kanamycin selection has already allowed the selection of transgenic lines containing a gene involved in nitrogen metabolism (Tereso et al. 2003).

Effect of antibiotics on growth of embryogenic clumps

There were highly statistical significant differences in tissue growth between subcultures for the antibiotics cefotaxime, carbenicillin and timentin $(H(1)=23.92 ; p<0.001)$ as they were also for the different antibiotic concentrations used $(H(6)=104.89 ; p<0.001)$. Growth of embryogenic clumps was significantly inhibited by cefotaxime but only at $400 \mathrm{mg} \mathrm{l}^{-1}$ and in the second subculture (Fig. 2a). Tissue growth did not significantly differ from the first to the second subcultures only whem the antibiotic timentin was used. Carbenicillin at both concentrations tested significantly increased tissue growth in $P$. pinaster. In $P$. radiata embryogenic clumps, $400 \mathrm{mg} \mathrm{l}^{-1}$ carbenicillin also did not have a negative effect on tissue growth (Cerda et al. 2002). In Portuguese $P$. pinaster genotypes, timentin did not inhibit tissue growth and has already shown to be effective at $400 \mathrm{mg} \mathrm{l}^{-1}$ to control growth of Agrobacterium strain C58pMP90 in transformation of embryogenic clumps (Tereso 2005).

Regarding kanamycin treatments, differences in tissue growth of embryogenic clumps were highly statistical significant between subcultures $(H(1)=$ 39.71; $p<0.001)$ and among different antibiotic concentrations $(H(5)=41.01 ; p<0.001)$. Kanamycin significantly stimulated clump growth in the first subculture at $5 \mathrm{mg} \mathrm{l}^{-1}$ but it inhibited growth at all the concentrations above this, although only after the second subculture (Fig. 2b). At concentrations of $20-50 \mathrm{mg} \mathrm{l}^{-1}$ of kanamycin, this antibiotic even caused loss of weight from the tissues. In Agrobacterium-mediated transformation of Larix and Picea, 25-50 $\mathrm{mg} \mathrm{l}^{-1}$ kanamycin has been used successfully (Levée et al. 1997; Le et al. 2001). This suggests that the optimal antibiotic and concentration have to be found for each species, type of explant and contact between tissue and selection medium.

Antibiotic effect on adventitious bud induction on cotyledons

In general, the presence of cefotaxime or timentin in the concentrations tested (200-400 $\mathrm{mg} \mathrm{l}^{-1}$ ) had no negative effect on adventitious bud induction, as compared with the control (Fig. 3a). An exception was observed for family 45 , where significantly lower induction frequencies and bud number (Figs. 3a and 4a) were found when timentin or cefotaxime were used at the highest concentration tested $\left(400 \mathrm{mg} \mathrm{l}^{-1}\right)$. The adventitious bud number was not significantly different in the experiments using cefotaxime or timentin, and it was significantly higher in family 60 as compared to families 31 and 45 (Fig. 4a). In Agrobacterium-mediated transformation of Pinus organogenic tissues, antibiotics such as timentin (Charity et al. 2002; Grant et al. 2004) or cefotaxime with vancomycin (Humara et al. 1999; López et al. 2000) have been used. In P. glauca, up to $500 \mathrm{mg}^{-1}$ cefotaxime had no effect on bud formation, and up to $750 \mathrm{mg}^{-1}$ carbenicillin only slightly inhibited bud induction (Ellis et al. 1989). In conclusion, the susceptibility of bud forming cotyledons to antibiotics in $P$. pinaster may depend on the type and concentration of antibiotic and on the seed family of the cotyledon explants.

The strong inhibitory effect of kanamycin on adventitious bud formation in cotyledons was observed in all concentrations tested (Fig. 3b). 
The bud induction frequency at the lowest kanamycin concentration $\left(5 \mathrm{mg} \mathrm{l}^{-1}\right)$ was considerably reduced $(0-10 \%)$ when compared to the control (80-90\%) and at concentrations above $5 \mathrm{mg} \mathrm{l}^{-1}$ no buds were formed. In some Pinus species, very low-kanamycin concentrations can inhibit adventitious bud formation (Humara and Ordás 1999; Grant et al. 2004). This effect has been suggested as explainable by DNA hypermethylation, which has been shown to affect plant development (Schmitt et al. 1997). In the control, the number of buds produced per set of cotyledons was significantly higher in family 60 than in families 31 and 45. However, in the presence of kanamycin, these differences were not statistically significant, all values being significantly lower than that of the control (Fig. 4b). These results suggest that seed family does not significantly affect the organogenic response of cotyledons to kanamycin.

Present results showed the different susceptibility to kanamycin of $P$. pinaster explants, increasing from embryogenic tissues on filter paper to embryogenic clumps and being higher in cotyledons. Low-kanamycin concentrations were toxic to embryogenic tissues and cotyledons $\left(\geq 5 \mathrm{mg} \mathrm{l}^{-1}\right)$. Therefore, the use of other aminoglycosides analogs of kanamycin and selective systems for genetic transformation of this species should be considered. The antibiotics carbenicillin induced tissue growth when in direct contact with embryogenic clumps, possibly as a result of an auxin-like effect as was reported for carbenicillin in other species (Holford and Newbury 1992). The small or no negative effects of timentin on embryogenic tissue growth and adventitious bud induction, as reported for other species, makes it an alternative to the highly expensive and ineffective combinations of cefotaxime and carbenicillin. Results presented in this work will be crucial for the Agrobacteriummediated transformation of $P$. pinaster Portuguese genotypes.

Acknowledgments This research was supported by Fundação para a Ciência e Tecnologia (FCT) and the III Framework Programme of the European Community, through grants SFRH/BD/1186/2000 and SFRH/BPD/ 14964/2004 and Project POCTI/AGR/57157/2004. Estação Florestal Nacional (EFN) is acknowledged for making plant material available.

\section{References}

Cerda F, Aquea F, Gebauer M, Medina C, Arce-Johnson P (2002) Stable transformation of Pinus radiata embryogenic tissue by Agrobacterium tumefaciens. Plant Cell Tiss Org Cult 70:251-257

Charity JA, Holland L, Donaldson SS, Grace L, Walter C (2002) Agrobacterium-mediated transformation of Pinus radiata organogenic tissue using vacuum-infiltration. Plant Cell Tiss Org Cult 70:51-60

Conover WJ (1999) Practical nonparametric statistics. Wiley, New York

Ellis DD, Lazaroff WR, Roberts DR, Flinn BS, Webb DT (1989) The effect of antibiotics on elongation and callus and bud formation from embryogenic tissue of Picea glauca. Can J For Res 19:1343-1346

Grant JE, Cooper PA, Dale TM (2004) Transformed Pinus radiata from Agrobacterium tumefaciens-mediated transformation of cotyledons. Plant Cell Rep 22:894-902

Gupta PK, Durzan DJ (1985) Soot multiplication from mature trees of Douglas fir (Pseudotsuga menziesii) and sugar pine (Pinus lambertiana). Plant Cell Rep 4:177-179

Holford P, Newbury HJ (1992) The effects of antibiotics and their breakdown products on the in vitro growth of Antirrhinum majus. Plant Cell Rep 11:93-96

Holland L, Gemmell JE, Charity JA, Walter C (1997) Foreign gene transfer into Pinus radiata cotyledons by Agrobacterium tumefaciens. NZ J For Sci 27:289-304

Hood EE, Clapham DH, Ekberg I, Johanson T (1990) TDNA presence and opine production in tumors of Picea abies (L.) Karst induced by Agrobacterium tumefaciens A281. Plant Mol Biol 14:111-117

Humara JM, Ordás RJ (1999) The toxicity of antibiotics and herbicides on in vitro adventitious shoot formation on Pinus pinea L. cotyledons. In Vitro Cell Dev Biol-Plant 35:339-343

Humara JM, López M, Ordás RJ (1999) Agrobacterium tumefaciens-mediated transformation of Pinus pinea $\mathrm{L}$. cotyledons: an assessment of factors influencing the efficiency of uidA gene transfer. Plant Cell Rep 19:51-58

Klimaszewska K, Lachance D, Pelletier G, Lelu M-A, Séguin A (2001) Regeneration of transformed Picea glauca, $P$. mariana, and $P$. abies after cocultivation of embryogenic tissue with Agrobacterium tumefaciens. In Vitro Cell Dev Biol 37:748-755

Le VQ, Belles-Isles J, Dusabenyagasani M, Tembray FM (2001) An improved procedure for production of white spruce (Picea glauca) transformed plants using Agrobacterium tumefaciens. J Exp Bot 52:2089-2095

Levée V, Lelu M-A, Jouanin L, Cornu D, Pilate G (1997) Agrobacterium tumefaciens-mediated transformation of hybrid larch (Larix kaempferi X L. decidua) and transformed plant regeneration. Plant Cell Rep 16:680-685

Levée V, Garin E, Klimaszewska K, Séguin A (1999) Stable genetic transformation of white pine (Pinus strobus L.) after cocultivation of embryogenic tissues with Agrobacterium tumefaciens. Mol Breed 5:429-440 
López M, Humara JM, Rodríguez R, Ordás RJ (2000) Factors involved in Agrobacterium tumefaciens-mediated gene transfer into Pinus nigra Arn. ssp. Salzmannii (Dunal) Franco. Euphytica 114:195-203

Miguel C, Gonçalves S, Tereso S, Marum L, Oliveira MM (2004) SE from 20 open-pollinated seed families of Portuguese plus trees of maritime pine. Plant Cell Tiss Org Cult 76:121-130

Mihaljević S, Perić M, Jelaska S (2001) The sensitivity of embryogenic tissue of Picea omonika (Panč.) Purk. to antibiotics. Plant Cell Tiss Org Cult 67:287-293

Mohammed GH, Dunstan DI, Thorpe T (1986) Influence of nutrient medium upon shoot initiation on vegetative explants excised from 15 to 18-year-old Picea glauca. NZ For Sci 16:297-305

Sarma KS, Evans NE, Selby C (1995) Effect of carbenicillin and cefotaxime on somatic embryogenesis of Sitka spruce (Picea sitchensis (Bong.) Carr.) J Exp Bot 46:1779-1781

Schmitt F, Oakeley EJ, Jost JP (1997) Antibiotics induce genome-wide hypermethylation in cultured Nicotiana tabacum plants. J Biol Chem 272:1534-1540

Tereso S, Zoglauer K, Miguel C, Oliveira MM (2003) Genetic engineering as a tool for studies of nitrogen metabolism in maritime pine. In: International Congress Tree Biotechnology, June 2003, Ümea, Sweden

Tereso S (2005) In vitro culture systems for clonal propagation and genetic transformation of Pinus pinaster (Sol. ex Ait.). PhD Dissertation, Universidade Nova de Lisboa, Instituto de Tecnologia Química e Biológica, Oeiras, Portugal

Trontin J-F, Harvengt L, Garin E, Lopez-Vernaza M, Arancio L, Hoebeke J, Canlet F, Pâques M (2002) Towards genetic engeneering of maritime pine (Pinus pinaster Ait.). Ann For Sci 59:687-697

Tsang EWT, David H, David A, Dunstan DI (1989) Toxicity of antibiotics on zygotic embryos of white spruce (Picea glauca) cultures in vitro. Plant Cell Rep 8:214-216

Verbist L, Verhaegen J (1986) Susceptibility of tricarcillinresistant gram-negative bacilli to different combination of tricarcillin and clavulanic acid. J Antimicrob Chemother 17:7-15

Wenck AR, Quinn M, Whetten RW, Pullman G, Sederoff R (1999) High-efficiency Agrobacterium-mediated transformation of Norway spruce (Picea abies) and loblolly pine (Pinus taeda). Plant Mol Biol 39:407-416

Zar JH (1999) Biostatistical analysis. Prentice-Hall, Upper Saddle River, NJ 